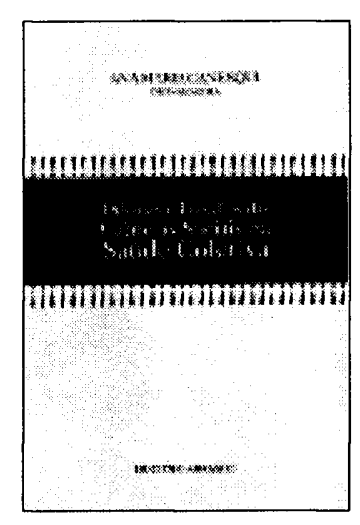

\title{
Comentários a "Dilemas e Desafios das Ciências Sociais na Saúde Coletiva"
}

Dilemas e Desafios das Ciências Sociais na Sañde ColetivaA. M. Canesqui (org.).

São Paulo/Rio de Janeiro: Hucite ABRASCO.

165 páginas.

Suely Ferreira Deslandes

Departamento de Ciências Sociais, Escola Nacional de Saúde Pública, Fundação Oswaldo Cruz.

O livro é uma coletânea que reúne diversos cientistas sociais. Seus artigos, na sua maioria, foram apresentados na "Oficina de Ciências Sociais em Saúde" (1995) e no "I Encontro Nacional de Ciências Sociais em Saúde (1993), ambos encontros promovidos pela ABRASCO.
A obra está organizada a partir de dois eixos temáticos: o primeiro aborda a inserção das Ciências Sociais na Saúde, enfocando sua institucionalização e trazendo os debates teórico-metodológicos mais contemporâneos das Ciências Sociais para o contexto da produção de pesquisa social em Saúde. O segundo trabalha a questão do ensino das Ciências Sociais em Saúde, enfatizando distintas experiências institucionais, os obstáculos e desafios encontrados e o processo de incorporação das Ciências Sociais no ensino 
médico e em Saúde Pública no país.

O capítulo inicial, "As Ciências Sociais, a Saúde e a Saúde Coletiva" de Canesqui, resgata a trajetória de incorporação das Ciências Sociais no campo da Saúde. Mais que uma síntese histórica, o trabalho constitui vigorosa análise sociológica sobre a construção de legitimidade, ao longo das últimas quatro décadas, das distintas temáticas e abordagens teórico-metodológicas que compõem o escopo das Ciências Sociais na área de Saúde Coletiva, contextualizando-as à luz das conjunturas e aspectos estruturais prevalecentes no Brasil e América Latina neste período.

Nunes assina o texto "As Ciências Sociais e a Saúde: O pensamento recente de alguns pesquisadores", onde analisa trabalhos bastante recentes apresentados numa das oficinas do I Encontro Brasileiro de Ciências Sociais em Satide. Revela o autor que apesar da diversidade dos temas, percebese nestes textos algumas preocupações teórico-metodológicas constantes: a tensão entre estrutura e a ação dos sujeitos sociais na explicação sociológica; a crise dos modelos clássicos de análise; a constituição de novos sujeitos e dos sujeitos coletivos, e sua participação em movimentos sociais distintos; e o universo dos significados como questão fundamental, mas pouco explorada na área da Saúde.

Tais preocupações são também compartilhadas por Alves ("A Perspectiva da Análise Social no Campo da Saúde: Aspectos metodológicos") e Ferreira ("Notas Sobre a Contribuição do Cientista Social ao Campo da Saúde"). Alves reconhece o predomínio da perspectiva estrutural-sistêmica nas pesquisas sociais desenvolvidas na Saúde na década de 80 , o que traz uma série de conseqüências metodológicas, entre elas: o de constituir o campo enquanto objeto da explicação científica; o "decifrar" racionalmente os códigos do sistema, subordinando o mundo real à sua apreensào conceitual, e produzindo análises baseadas em amplas formalizações teóricas. Ferreira aponta a interdisciplinaridade como uma alternativa imposta pelo desafio de não reconstruir uma teoria "total", nem cair nas armadilhas das "micro" teorias. Ambos reafirmam a importância do exercício hermenêutico no processo de interpretação dos fatos sociais e da busca do significado das ações humanas no contexto do vivido.

Seguindo esta linha discursiva, Machado ("Macro-Micro: Os novos desa- fios da sociologia e os efeitos no campo da Saúde") reconstitui a discussão entre os principais interlocutores das tradições estruturais e as vertentes metodológicas individualistas com relação à análise das relações sociais. Seu trabalho enfoca alguns dos desafios que a micro-sociologia impôs à macro-sociologia, especialmente no campo da Saúde, onde a necessidade de se entender detalhadamente a complexidade de determinados processos sociais constitui questão estratégica (sobretudo, no que diz respeito à organização do Sistema Público de Saúde). A autora trabalha a questão através de um exemplo que conhece profundamente: a análise dos recursos humanos. Machado reconhece que o grande desafio continua sendo o de se articular micro/macro. sem que se reduza uma perspectiva de abordagem à lógica da outra.

A questão da interdisciplinaridade assinala novamente a competente autoria de Nunes ("A Questão da Interdisciplinaridade no Estudo da Saúde Coletiva e o Papel da Ciências Sociais") que propõe uma reflexão acerca da importância e da viabilidade do projeto interdisciplinar na Saúde Coletiva e do papel que as Ciências Sociais podem desempenhar neste projeto. Esse 
debate ganha imensa visibilidade quando reconhecemos que o conceito ampliado de Saúde, categoria base da Saúde Coletiva, é, por definição, "integral", e não se esgota num único campo disciplinar, muito menos na mera justaposição de diversas disciplinas e saberes. Por outro lado, as dificuldades inerentes aos estudos que articulam processos sociais e eventos mórbidos, constituem ainda um desafio na tarefa urgente de se criar "novas alianças" entre o devir natural e cultural, possibilitando um conhecimento mais "complexo" e criativo.

Stotz ("Movimentos Sociais e Saúde: das dificuldades em incorporar a temática às reflexões teórico-metodológicas") denuncia a forma marginal como tem sido tratada a questão dos movimentos sociais em Saúde. O autor percebe um "atraso teórico" no tratamento dessa temática que se deve, entre outros motivos, à priorização, por parte do movimento de Reforma Sanitária das questões jurídico-legais e de engenharia institucional. $O$ autor aponta algumas formas de superação desse impasse, como a retomada do debate teórico sobre a especificidade do Estado na América Latina e suas relações com a sociedade civil, e a análise das políticas públicas a partir de um contexto relacional entre economia e política, democracia e desigualdade, Estado e sociedade. Stotz também considera como cruciais para se pensar o controle social das políticas públicas de Saúde, a discussão sobre a reconceitualização da proposta de cidadania e o esvaziamento dos processos de sua institucionalização no país, assim como a crise de poder instituinte do Estado.

Num segundo momento, a obra discute o processo histórico do ensino de Ciências Sociais na área de Saúde Pública e Coletiva. Somarriba ("As Ciências Sociais em Saúde e o Ensino: Notas para um debate"), a partir de sua experiência em lecionar Sociologia da Saúde em cursos de graduação e pós-graduação na Universidade Federal de Minas Gerais, enfatiza a relação entre as transformações sociais e de paradigmas pós-década de 70 e seu impacto nos currículos e disciplinas que ministram conteúdos do Pensamento Social em Saúde.

O texto de Marsiglia \& Spinelli e o texto de Adorno (capítulos 8 e 9) têm em comum a abordagem dos problemas enfrentados no ensino de conteúdos sociológicos na área de Saúde. A existência de uma clientela heterogênea e sem formação na área, os preconceitos enfrentados no dia- a-dia desses mestres e os obstáculos colocados ou não resolvidos pelas instituições constituem o tema comum destas reflexões. Contudo, não apresentam os autores uma visão derrotista, ao contrário enfatizam os meios e estratégias experimentadas por estes professores para a resolução de impasses.

O capítulo final de L'Abbate, escrito a partir da análise de uma avaliação proposta a alunos de um curso de especialização em Saúde Pública, discute as dificuldades e o desafio em se formar sanitaristas, sujeitos de novas práticas de saúde e cidadania, que contribuam para a construção do SUS numa perspectiva de competência, definida pelos níveis técnico-instrumental, político-crítico e ético. Ressalta que este processo dever ser alicerçado em Projetos de Educação Continuada e na supervisão e apoio aos projetos desenvolvidos pelos egresssos dos cursos.

Revendo o título, percebe-se que o projeto acadêmico contido no livro foi alcançado e que, sem dúvida, ele constitui leitura fundamental para todos aqueles que desejam conhecer e discutir criticamente os principais dilemas e desafios que as Ciências Sociais enfrentam hoje no campo da Saúde Coletiva. 